\title{
Experimental study on capillary water absorption of sandstones from different grotto heritage sites in China
}

Yue Zhang ${ }^{1,2^{*}}$, Yunmeng Zhang ${ }^{2}$ and Jizhong Huang ${ }^{2}$

\begin{abstract}
Sandstone grottoes, with their elaborate carvings and decorations, hold high historic, artistic and scientific values and therefore constitute an important part of China's stone cultural heritage. Although capillary water accounts for severe pathologies at the grottoes, so far there have been limited comprehensive investigations concerned with the capillary water absorption behavior of sandstones. Aiming at three significant and famous sites in China, i.e., Yungang Grottoes (YG), Dazu Rock Carvings (DZ) and Leshan Grand Buddha (LS), capillary water absorption tests were performed on samples from local sandstones. During the test, evolution of cumulative inflow was measured and variation in the height of capillary rise over time was also monitored by combining visual observation and infrared thermography. Scanning electron microscope and mercury intrusion porosimetry were adopted to characterize the pore structure. The results indicate that all the tested sandstones had a medium capacity of water uptake. Kinetics for capillary water absorption was the highest for LS sandstone and the lowest for DZ sandstone. Differences in macroscopic properties were contributed to microstructural features such as average pore diameter and pore size distribution. An irregular shaped water front was only observed in LS sandstone due to its heterogeneity. Infrared thermography provides an efficient and nondestructive way to detect the transition zone between wet and dry portions of the sample, which was not visible to the naked eyes. A proper understanding of the interaction of the sandstones with capillary water is essential for revealing the deterioration of grottoes and the underlying mechanisms.
\end{abstract}

Keywords: Stone heritage, Capillary rise, Water front, Microstructure, Infrared thermography, Deterioration

\section{Introduction}

China's grotto sites, distributed all over the country, are masterpieces of abundant stone carvings, stone tablets, murals and clay sculptures, reflecting the evolution history of Chinese Buddhist art. After hundreds or even thousands of years of exposure to natural weathering, these precious heritage sites suffered from severe and complicated deterioration. In fact, over $80 \%$ of these grottoes are carved in sandstone, a relatively loose and weak-bonded composite with numerous pores of various

\footnotetext{
*Correspondence: 2019zhangy@shu.edu.cn

1 Shanghai Institute of Applied Mathematics and Mechanics, School of Mechanics and Engineering Science, Shanghai University, Shanghai 200444, China

Full list of author information is available at the end of the article
}

sizes and shapes between the particles. When getting in touch with surrounding water, such as groundwater or rainwater, the pore network promotes absorbing, transporting and retaining the liquid inside of the stone.

Issues related to moisture, especially the capillary water, are common for stone buildings and broadly vary in types and consequences affecting the material's long-term durability. At the capillary zone of numerous historic stone structures, pathologies such as contour scaling, splitting, crumbling, crust, salt efflorescence and subflorescence, as well as lichen colonization were extensively observed [1-9]. As probably one of the most harmful agents, capillary water is correlated directly or indirectly with a variety of damaging processes including drying-wetting cycles, freezing-thawing cycles, salt

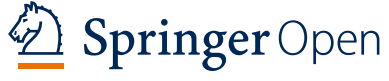

(c) The Author(s) 2022. Open Access This article is licensed under a Creative Commons Attribution 4.0 International License, which permits use, sharing, adaptation, distribution and reproduction in any medium or format, as long as you give appropriate credit to the original author(s) and the source, provide a link to the Creative Commons licence, and indicate if changes were made. The images or other third party material in this article are included in the article's Creative Commons licence, unless indicated otherwise in a credit line to the material. If material is not included in the article's Creative Commons licence and your intended use is not permitted by statutory regulation or exceeds the permitted use, you will need to obtain permission directly from the copyright holder. To view a copy of this licence, visit http://creativecommons.org/licenses/by/4.0/. The Creative Commons Public Domain Dedication waiver (http://creativeco mmons.org/publicdomain/zero/1.0/) applies to the data made available in this article, unless otherwise stated in a credit line to the data. 
crystallization and biological growth. Consequently, capillary water can negatively impact the physical and mechanical properties of stone and eventually cause material losses. Such phenomena undoubtedly emphasize the necessity to identify the interaction between stones and capillary water. Relevant knowledge would lay a foundation for understanding deterioration mechanisms and proposing proper conservation strategies for stone heritage.

So far, relevant kinetics of capillary action in porous materials have been widely investigated through laboratory work. In most cases, the quantity as well as the speed of water penetrating into stone was determined via the gravimetric method in accordance with international standards [10-16]. By weighing samples at regular time intervals, it was found that the capillary absorption potential is dominated by intrinsic factors of the stone material itself, i.e., the petrographic and structural characteristics. In addition, environmental factors such as temperature [17] and type of imbibed liquid [18] influence the surface tension and viscosity of the pore fluid and can alter the capillary water absorption capacity of the stone.

The gravimetric method reflects the material's overall hydraulic behavior. To obtain more details about water transportation via the pore system, in the conservation field, there has been a growing interest in studying the capillary front motion, as this process is vital for evaluating the vulnerability of stone to decay. Due to the lack of standard testing procedures, Karoglou et al. [19] estimated the variation in height of capillary rise from the obtained weighing data, by assuming that these two parameters were proportional magnitude. Some researchers distinguished the contact line between wet and dry zones on the sample directly through visual observation to monitor the time-dependent water rise [3, $16,20]$. To further quantify water distribution along the height during imbibition, Tsunazawa et al. [20] cut the stick-shaped sandstone samples into pieces. They found that water saturation remained almost constant at $52 \%$ from the bottom of the sample to approximately $70 \%$ of the capillary rise height, above which the water saturation decreased rapidly.

Over the last decades, more and more noninvasive and nondestructive techniques have been adopted to trace fluid flow within porous media. Nuclear magnetic resonance (NMR) as well as magnetic resonance imaging (MRI), which are tuned to excite the hydrogen nucleus, are particularly sensitive to water molecules [21, 22]. After soaking sandstone in distilled water for a fixed time duration, MRI clearly reveals the gradual water migration, in the subsequent standing period, from the surface of the sample towards its core [23]. Another powerful technique for detecting the dynamics of hydrogen-rich fluid in non-hydrogenous materials is neutron radiography, which can show a strong contrast between wet and dry portions $[24,25]$. By means of this method, Raneri et al. [26] obtained the position of the capillary front during imbibition and further prepared contour maps of water content by estimating the thickness of water and stone sample crossed by the neutron beam. In addition, $\mathrm{X}$-ray computerized tomography (X-CT) has also been successfully applied by David et al. [27, 28] to visualize water content profiles in sandstones and carbonate rocks. In their work, influences of anisotropy, heterogeneity and microstructure on the kinetics of the capillary front motion were discussed in detail. An interesting finding is that the geometry of the capillary front, flat or upward/downward concave, kept evolving at different imbibition stages. Recently, the application of electrical resistance measurement for monitoring capillary water motion in stones has been reported [29]. The authors noted that this method can be used as an indirect way for water detection, and accurate calibration is necessary before the formal test to acquire a relationship between water saturation and electrical resistance of the material. Besides, high sensitivity of electrical resistance to soluble salts in the fluid should be assessed carefully.

Regardless of the feasibility and efficacy in monitoring water migration in stone materials, wide application of the above-mentioned nondestructive instrumental analysis methods is restricted to some degree, because of their high cost, difficult operation and complex data processing. In contrast, infrared thermography (IRT) has been successfully employed both in the laboratory [30-32] and on site [33-35]. Portable IRT devices allow not only for a rapid detection of thermal energy distribution on a large object, but also for real-time imaging of the local temperature differences to help distinguish wet and dry areas. The method has its limitations, such as requiring the presence of water in near-surface regions and not always being precise under complicated microclimate conditions. For more accurate monitoring of water deep inside the material, other nonintrusive devices such as moisture meter and microwave sensors are also required [36-38]. Nevertheless, IRT has been regarded as a fast and convenient method to give a good overview of moisture conditions in a qualitative way.

To date, there are numerous papers concerned with the capillary imbibition of building stones on an international scale. However, relevant investigations in China, particularly aiming at the conservation problematics of sandstone grottoes, are far from sufficient. The capillary water absorption behavior of different sandstones has not been fully characterized and limited knowledge about this process might put barriers to sustainable conservation 
of these heritage sites. In this work, sandstones from three important grottoes in China were experimentally studied. During the capillary water absorption test, the evolution of cumulative inflow was measured by weighing at regular intervals, while simultaneously monitoring the height of capillary rise by combining visual observation and infrared thermography. The microstructure of the sandstones was characterized and compared using scanning electron microscope (SEM) and mercury intrusion porosimetry (MIP) to further interpret macroscopic properties.

\section{Background of the studied grotto sites}

There are many sandstone grottoes in different regions of China. This study focuses on three representative sites, i.e., Yungang Grottoes, Dazu Rock Carvings and Leshan Grand Buddha, which are listed as the National Key Cultural Relics Protection Units and World Heritage Sites for their outstanding universal values (Fig. 1).

The Yungang Grottoes are located at the southern foot of Wuzhou Mountain, $16 \mathrm{~km}$ west of Datong City in Shanxi Province. They were first carved under the charge of royalty in $453 \mathrm{AD}$ during the Northern Wei Dynasty, extending for $1 \mathrm{~km}$ from east to west. Until today, about 51,000 statues with sizes ranging from only $2 \mathrm{~cm}$ to $17 \mathrm{~m}$ height have remained in 45 major caves and 252 shrines [39]. The artwork exerted a far-reaching impact on the early stage of development of Buddhist cave art in China and East Asia. The site lies in the northwestern limb of the Jinhuagong Syncline and the outcrop of sedimentary strata is dominated by Middle Jurassic Yungang Formation, which is mainly a lens body of medium- to coarsegrained quartz sandstone interlayered with mudstone and sandy mudstone [40]. The sandstone beds, which mostly lie in the direction of NE, and EW subsidiary, have no fold but many inherent fractures. Bounded by a ridge line on the north side and valleys and rivers on the south, the whole area of the grotto site is widely covered by two layers of quaternary sediments. The groundwater level is about $10 \mathrm{~m}$ below its bottom so that the whole body of grottoes is completely in the aeration zone.

The Dazu Rock Carvings were built in the steep hillsides in Dazu District of Chongqing City from the 9th to thirteenth centuries. There are five important clusters of rock carvings in this area that represent the highest level of Chinese cave art at that time [41]. The carvings are famous for their rich diversity of secular subject matter and harmonious coexistence of different religions (Buddhism, Confucianism and Taoism), showing major changes in aesthetic style throughout history. The U-shaped Dafo Bay at Baoding Mountain is the most outstanding site among the Dazu Rock Carvings. It has the typical geomorphology of a deep gully around which all rock carvings are located at a steep cliff. The Niche of Sakyamuni Entering Nirvana, a large and impressive carving in Dafo Bay, lies in the east hillside with SN orientation and there is a permanently water-filled Shengji pool (about $1000 \mathrm{~m}^{2}$ ) located in its eastern area [42]. The local sandstone is shallow-water fluvial and lacustrine sediment of the Upper Jurassic Penglaizhen Formation in the Sichuan Basin. It is mainly composed of medium- to fine-grained feldspar quartz sandstone and some mudstone intercalation with horizontal bedding and parallel bedding structure. Typically, the rock mass in the grottoes area remains relatively dry. During intensive rainfall events, some of the water penetrates downward into

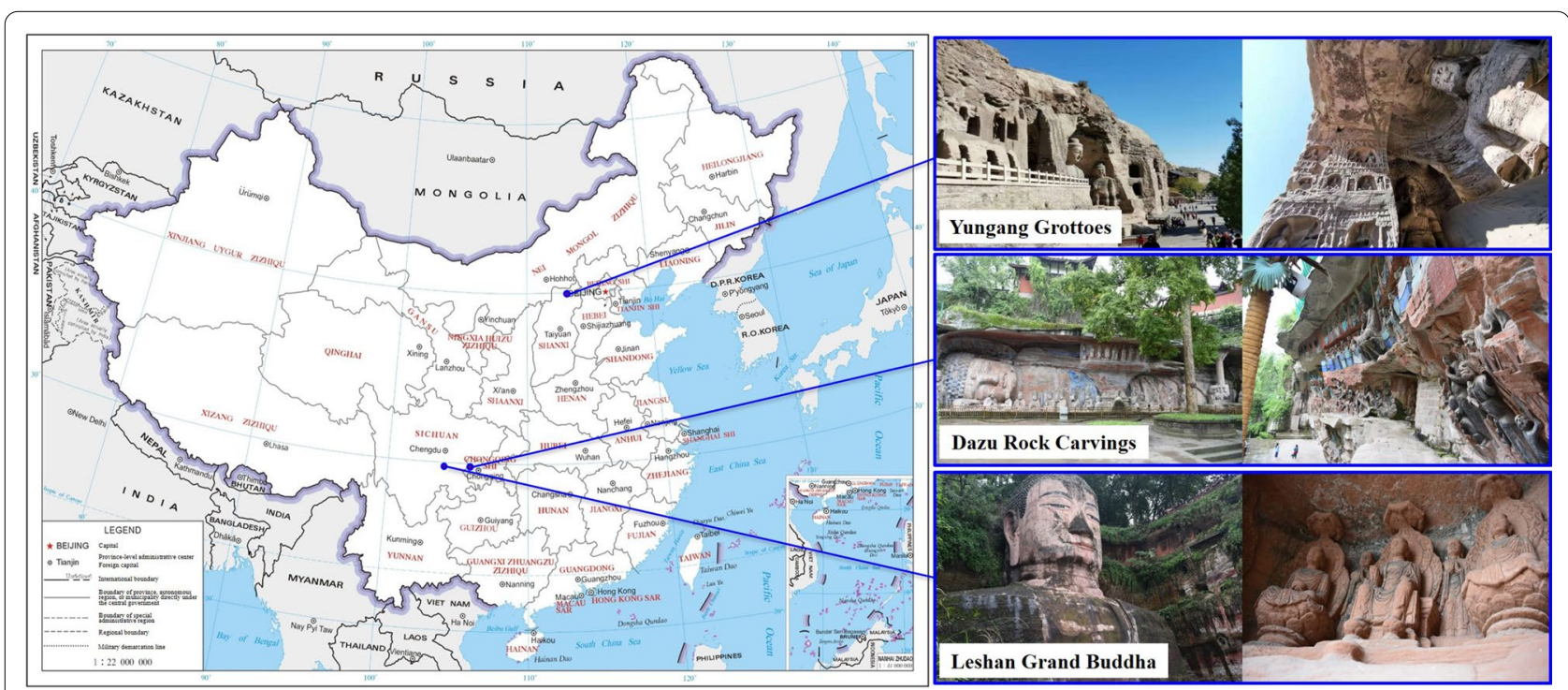

Fig. 1 Overview of three significant sandstone grotto sites in China 
the quaternary sediments and weathered bed rock while most of it is discharged to Dafo Bay through surface runoff.

Leshan Grand Buddha is situated on the western cliff of Lingyun Mountain in Leshan City, Sichuan Province at the convergence of Mingjiang River, Qingyi River and Dadu River. Its construction lasted from 713 AD until 803 AD during the prosperous Tang Dynasty. As the largest sitting image of Maitreya Buddha in the world (71 $\mathrm{m}$ high), this lithoid statue is attractive for its dignified posture and benevolent countenance. More than 200 niches with sculptures and tablets were carved on the cliffs nearby. Due to the weak influence of geological tectonic movements, the bedrock in this area has a clear stratigraphic sequence and stable occurrence without any obvious folds and fractures. The outcrop of strata in this region is the lower part of the Upper Cretaceous Jiaguan Formation dominated by medium- to fine-grained red sandstone [43]. The main grains of quartz and feldspar are bonded by calcareous, siliceous and ferruginous cements. The groundwater has a recharge-discharge relation with Mingjiang River and its water level is lower than the foundation of the Grand Buddha. The presence of weak mudstone intercalated layers leads to local seepage at the shoulders, chest and knees of the statue, particularly in the rainy seasons.

The Yungang Grottoes, located in northern China, are subjected to a temperate continental semi-arid monsoon climate. The main characteristics of this climate are the obvious seasonal changes in temperature and the concentrated heavy rainfall events especially in the summer. In comparison, Dazu Rock Carvings and Leshan Grand Buddha lie in the southwest area of the country. The local climate is quite warm and humid with a mean annual precipitation usually exceeding $1000 \mathrm{~mm}$. Despite the quite different engineering geological and environmental conditions, all these heritage sites have inevitably suffered from rising damp and related deterioration processes. Various pathologies, especially at the capillary zone of structures, can be observed in forms such as granular disintegration, multiple flaking, cracking, roughening, discoloration (moist area), biological and microbiological colonization (Fig. 2). Both the aesthetic and geotechnical features of the grottoes are affected by deterioration, exerting severe threat on their long-term preservation.

\section{Materials and methods}

\section{Sampling and sample preparation}

It is essential to ensure homogeneity between the tested samples and the sandstone constituting the artwork. For sampling, outcrops of contemporaneous strata that extend horizontally to the grottoes were therefore
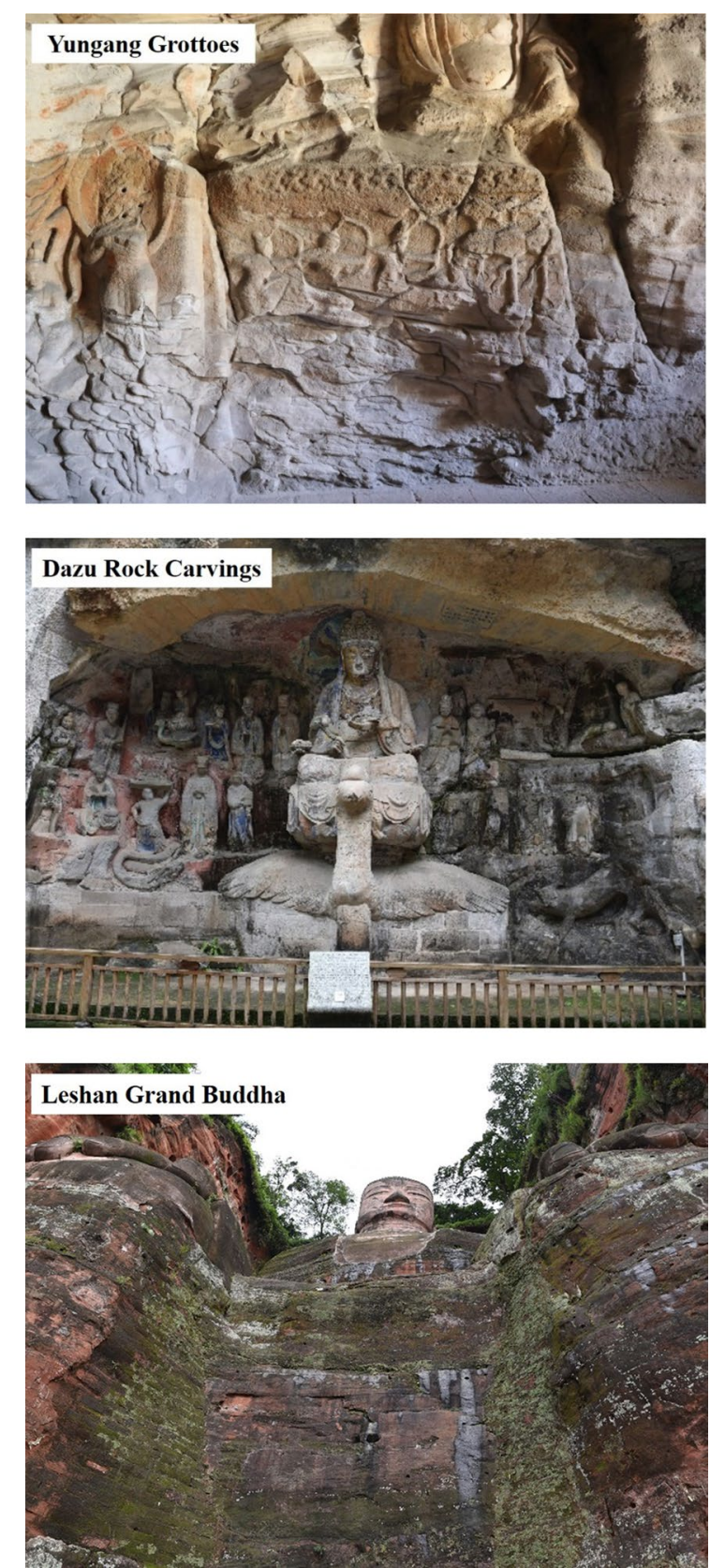

Fig. 2 Deterioration at the capillary zone of the studied grotto sites

carefully selected based on detailed geological investigation. Yungang (YG) and Leshan (LS) sandstones were obtained from hills close to the grottoes. Dazu (DZ) sandstone was collected on top of the Niche of Sakyamuni Entering Nirvana in Dafo Bay at Baoding Mountain. To avoid possible heterogeneity induced by weathering effects, fresh sandstone at depth greater than $20 \mathrm{~cm}$ from the external surface was extracted. 
Large blocks were then cut into small columns $(50 \mathrm{~mm}$ in diameter, $100 \mathrm{~mm}$ in height) in perpendicular direction to the bedding plane and polished except for the bottom surface. All samples were completely dried to a constant mass at $105^{\circ} \mathrm{C}$ in a ventilated oven to eliminate the existing moisture. After cooling down to room temperature in a desiccator, $\mathrm{P}$-wave velocity of each sample was measured along its height using an ultrasonic tester with two transducers (a transmitter and a receiver). In this way, parallel samples can be screened out to guarantee their similarity and to minimize test errors. General macroscopic views of the three tested sandstones are illustrated in Fig. 3.

\section{Sandstone characterization}

The basic physical properties of the three sandstones were determined in accordance with the standards [44, 45]. From the oven-dried samples, the initial solid mass was weighed and the apparent volume was measured on the basis of its dimension. The sample was then immersed completely in distilled water for $48 \mathrm{~h}$ at atmospheric pressure (free condition) and in an evacuation vessel at a pressure of $2 \mathrm{kPa}$ (forced condition), respectively, until reaching constant mass. Water absorption under each condition was expressed as the mass ratio of absorbed water and oven-dried sample in form of percentage. The apparent density of the samples was dependent on the initial solid mass and apparent volume. Open porosity reflects the ratio of the volume of open pores in the sample to its apparent volume, in which the former parameter can be obtained from the mass of absorbed water under forced condition.

The mineralogical and petrographic features of the three sandstones were characterized at the Micro Structure Analytical Laboratory. To determine the composition and content of minerals including clay fraction $(<2 \mu \mathrm{m})$, a Bruker D8 Advance X-Ray diffractometer with $\mathrm{CuK \alpha}$ radiation was utilized to perform analysis from $5^{\circ}$ to $70^{\circ} 2 \theta$ with a step increment of $0.02^{\circ}$ and a scanning speed of $2 \% \mathrm{~min}$. Data processing was achieved using Jade version 9.0 software from Materials Data Inc. (MDI). Polished thin sections about $30 \mu \mathrm{m}$ in thickness were prepared and examined under a polarizing microscope (CNOPTEC Smart-pol). In addition, the microstructure

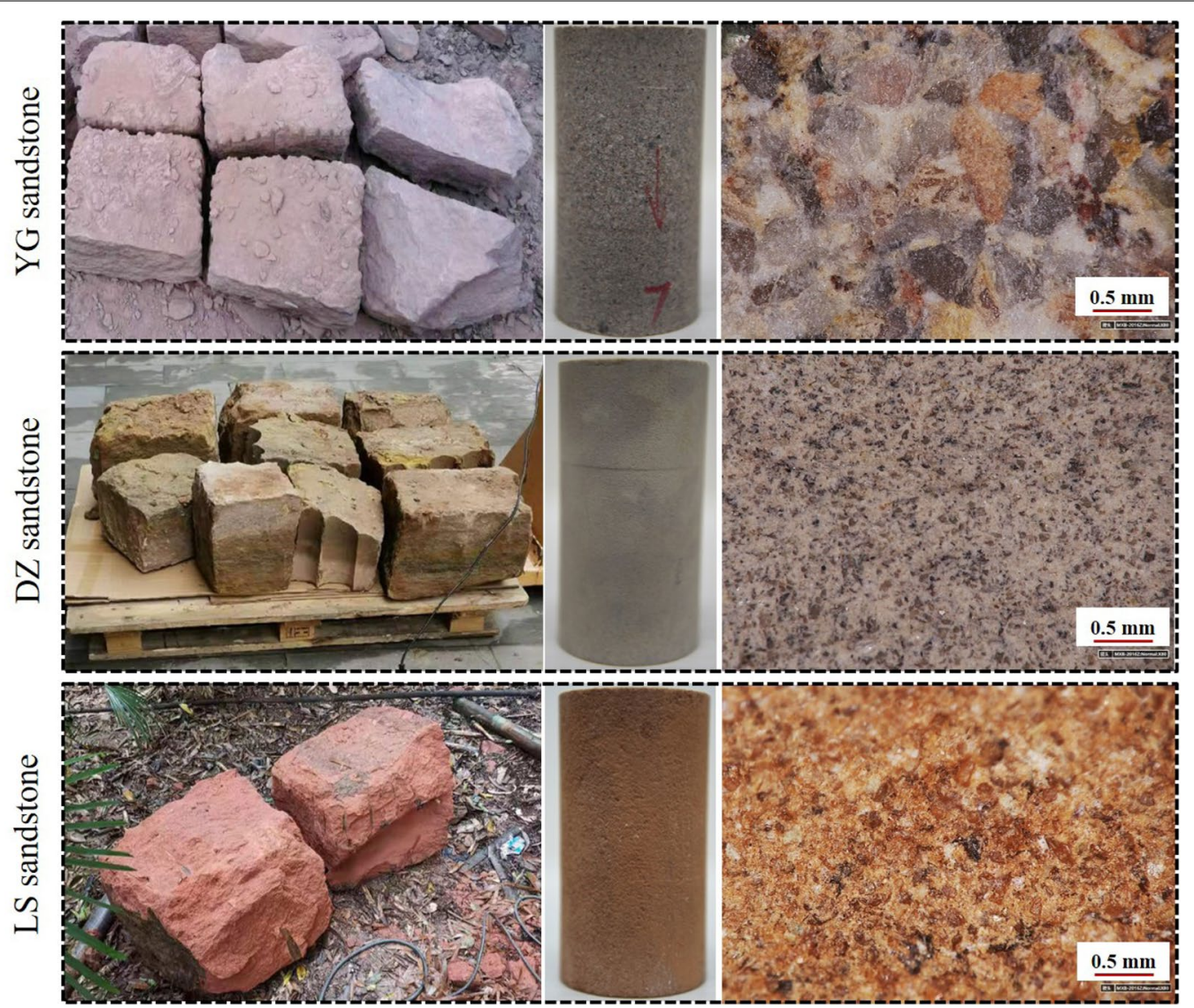

Fig. 3 General macroscopic views of the tested sandstones 
of each sandstone was analyzed on dry samples by combining SEM and MIP. A cold field scanning electron microscope (JSM-6700F) in Shanghai University and a porosimeter (Micromeritics Instrument AutoPore IV 9500) in Shanghai Zhengkuai Instrumental Analysis Technology Service Center were adopted, respectively. MIP test is capable of measuring pore diameters over a wide range from 0.005 to $360 \mu \mathrm{m}$.

\section{Capillary water absorption test}

The capillary water absorption characteristics of the three sandstones were measured quantitatively in the laboratory. The room temperature and relative air humidity remained at $26 \pm 1{ }^{\circ} \mathrm{C}$ and $35 \pm 5 \%$, respectively. Detailed test procedure is described as follows.

A container with a solid bracket at its bottom was prepared and distilled water was filled in to keep the water level approximately $2 \mathrm{~mm}$ higher than the bracket. Then, the oven-dried samples were put on the supporting bracket for partial immersion in the water, inducing onedimensional water absorption by capillarity. The contact area of the bracket with the sample should be as small as possible to ensure an undisturbed imbibition process.

During the test, the samples were taken out of the container at regular intervals. After gently removing the excess water attached to the bottom surface with a moist cloth, each sample was weighed using an electronic balance (a precision of $0.01 \mathrm{~g}$ ). In the meantime, the variation in the height of capillary rise was monitored by two methods. The position of the water front was recognized through visual observation based on the boundary line between the wet and dry portions. A ruler was adopted to measure the corresponding distance between water front and the bottom surface of the sample directly. Four different points along the circumference were chosen for measurement, considering the average value as capillary rise height at the given moment. Further, a FLIR A615 infrared camera (uncooled focal plane array, $17 \mu \mathrm{m}$ pitch, $<50 \mathrm{mK}$ thermal sensitivity) was applied to take images of the sample. This device has a resolution of $640 \times 480$ pixels and a wavelength range varying from 7.5 to $14 \mu \mathrm{m}$. Its measurement accuracy is $\pm 2{ }^{\circ} \mathrm{C}$ or $\pm 2 \%$ of reading. The obtained time-lapse series of thermographs were treated later with the FLIR Tools + software using a color scale for the representation of surface temperature. This measurement procedure was conducted as quickly as possible, after which the samples were put back into the container for continuous absorption. During the capillary imbibition, the container was covered to avoid intense evaporation. Distilled water was carefully added to maintain a constant water level when necessary. The test was finally stopped when the sample reached a constant weight, i.e., the difference between two successive measurements was no greater than $1 \%$ of the mass of water absorbed by the sample.

\section{Results and discussions}

Mineralogical, petrographic and petrophysical properties

As summarized in Table 1, although the apparent densities of the tested sandstones were similar, obvious differences existed among their open porosities ranging from $7.69 \%$ for DZ sample to $13.02 \%$ for LS sample. The open porosity includes only pores that are open to the outside of the material. Hence, as expected, LS sandstone was the most water-absorbent, both under free and forced conditions, due to its larger quantity of open pores.

The results of the XRD analyses are given in Table 2 . Mineralogical compositions of all the tested sandstones consisted mainly of quartz with a small amount of calcite and microcline as well as a trace of hematite. In YG sandstone, albite was absent whereas its clay content was almost two times that of the other sandstones. The predominant clay mineral type in YG, DZ and LS samples was kaolinite, mixed layer of chlorite/smectite and mixed layer of illite/smectite, respectively. Figure 4 presents the photomicrographs of thin sections of the tested sandstones and their petrographic features are summarized in Table 3. The composition of these sandstones mostly included quartz, K-feldspars, plagioclase, lithic fragments and minor amounts of mica. The quartz mainly occurred as monocrystal and calcite cement filled the pores between the framework grains that were generally subrounded to sub-angular. Based on the varying range of

Table 1 Basic information of the tested sandstones

\begin{tabular}{|c|c|c|c|c|c|c|c|}
\hline \multirow[t]{2}{*}{ Sample } & \multirow{2}{*}{$\begin{array}{l}\text { Age of } \\
\text { stratum }\end{array}$} & \multicolumn{6}{|c|}{ Physical properties } \\
\hline & & Color & $\begin{array}{l}\text { Apparent density } \\
\left(\mathrm{kg} / \mathrm{m}^{3}\right)\end{array}$ & $\begin{array}{l}\text { Open porosity } \\
(\%)\end{array}$ & $\begin{array}{l}\text { Free water absorption } \\
\text { (mass, \%) }\end{array}$ & $\begin{array}{l}\text { Forced water } \\
\text { absorption } \\
\text { (mass, \%) }\end{array}$ & $\begin{array}{l}\text { P-wave velocity } \\
(\mathrm{km} / \mathrm{s})\end{array}$ \\
\hline YG & $J_{2 y}$ & Sandy brown & $2436( \pm 219)$ & $9.64( \pm 0.73)$ & $3.16( \pm 0.15)$ & $3.95( \pm 0.19)$ & $2.88( \pm 0.23)$ \\
\hline DZ & $J_{3 p}$ & Beige, grayish & $2380( \pm 202)$ & $7.69( \pm 0.62)$ & $2.31( \pm 0.08)$ & $3.23( \pm 0.12)$ & $2.82( \pm 0.24)$ \\
\hline LS & $K_{2 j}$ & Brownish red & $2328( \pm 256)$ & $13.02( \pm 1.43)$ & $3.34( \pm 0.23)$ & $5.59( \pm 0.29)$ & $2.55( \pm 0.28)$ \\
\hline
\end{tabular}

Note: The average value of each parameter is listed with the standard deviation (SD) indicated in brackets 
Table 2 Mineralogical composition of the tested sandstones by XRD analysis

\begin{tabular}{|c|c|c|c|c|c|c|c|c|c|c|c|c|}
\hline \multirow[t]{2}{*}{ Sample } & \multicolumn{6}{|c|}{ Content of whole rock minerals (\%) } & \multicolumn{6}{|c|}{ Relative content of clay minerals (\%) } \\
\hline & Quartz & Calcite & Microcline & Hematite & Albite & Clay & $\mathrm{s}$ & $\mathrm{I} / \mathrm{S}$ & 1 & $\mathrm{~K}$ & $\mathrm{C}$ & $\mathrm{C} / \mathrm{S}$ \\
\hline YG & 62 & 4 & 7 & 1 & - & 27 & - & 6 & 15 & 79 & - & - \\
\hline DZ & 57 & 12 & 4 & 1 & 13 & 13 & - & 23 & 17 & 2 & - & 58 \\
\hline LS & 58 & 10 & 4 & 1 & 12 & 15 & - & 61 & 34 & 5 & - & - \\
\hline
\end{tabular}

Note: $\mathrm{S}=$ smectite, $\mathrm{I}=$ illite, $\mathrm{K}=$ kaolinite, $\mathrm{C}=$ chlorite, $\mathrm{I} / \mathrm{S}=$ mixed layer of illite/smectite, $\mathrm{C} / \mathrm{S}=$ mixed layer of chlorite/smectite
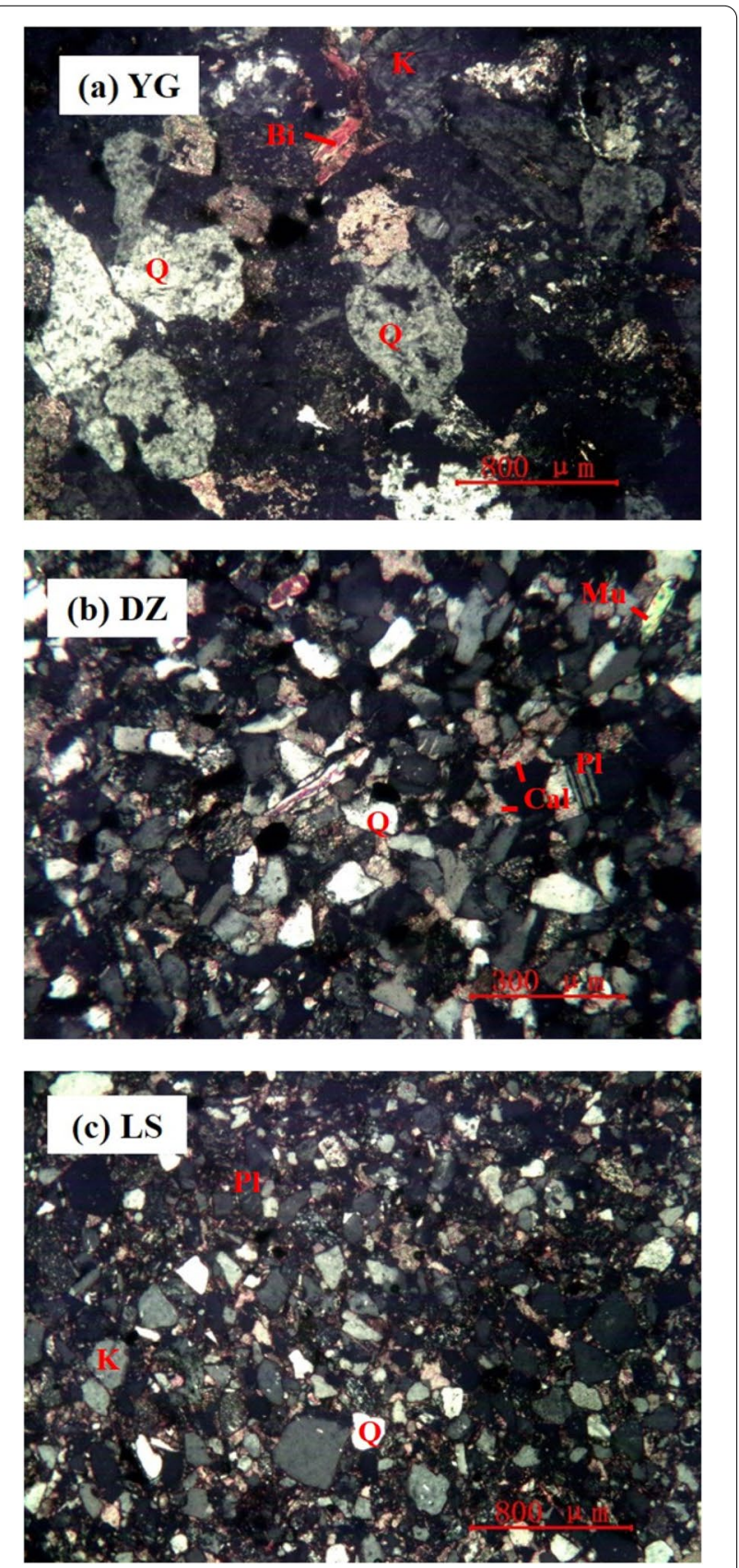

Fig. 4 Photomicrographs of texture of the tested sandstones on thin-sections grain size, YG, DZ and LS sandstones were characterized as coarse-grained lithic quartzose sandstone, fine-grained feldspathic sandstone and medium- to fine-grained lithic feldspathic sandstone, respectively.

The SEM microphotographs show that grains of YG sandstone were relatively large, flat and well-bonded (Fig. 5). In comparison, DZ and LS sandstones contained many rounded and finer grains. As mentioned before, compared to the others, LS sandstone had a larger porosity due to its loose compaction and a lower clay content. Consequently, it exhibited a more porous structure with looser contact and less cementation between adjacent particles.

Figure 6 presents the curves obtained from MIP tests by plotting the cumulative volume and log-differential volume of mercury against pore diameter. The cumulative mercury intrusion per gram of the sample was comparable for YG sandstone $(0.0493 \mathrm{~mL} / \mathrm{g})$ and LS sandstone $(0.0486 \mathrm{~mL} / \mathrm{g})$. This value decreased slightly for $\mathrm{DZ}$ sandstone $(0.0435 \mathrm{~mL} / \mathrm{g})$ indicating its lower porosity. The pore size distribution (PSD) curves of YG and DZ sandstones can be both characterized as unimodal types because most of the pore sizes concentrate at a relatively narrow range. The peak pore diameter on each curve corresponded approximately to $0.554 \mu \mathrm{m}$ and $0.284 \mu \mathrm{m}$, respectively. Note that the PSD curve of LS sandstone had multiple peaks at about $11.334 \mu \mathrm{m}$ and $0.549 \mu \mathrm{m}$ but with lower intensity. A certain number of pores larger than $100 \mu \mathrm{m}$ were also present.

Pores in stone can be divided into three types based on their sizes: micropores $(<0.1 \mu \mathrm{m})$, mesopores $(0.1-$ $2500 \mu \mathrm{m})$, and macropores $(>2500 \mu \mathrm{m})$ [46]. In some cases, the boundary between mesopores and macropores is also set at $1000 \mu \mathrm{m}$ [11]. It is clear that the tested sandstones were all dominated by mesopores and their micropores were similar in values varying between 21.05 and $26.86 \%$ (Table 4 ). It is worth mentioning that the LS sample had much more pores over a diameter of $1 \mu \mathrm{m}$ as compared to the other two samples.

Some characteristic pore diameters of each sandstone are listed in Table 4. Dominant pore diameter range corresponds to the zone between the starting and ending points of the sharp increase on the cumulative mercury 
Table 3 Petrographic features of the tested sandstones by thin-section analysis

\begin{tabular}{|c|c|c|c|c|c|c|}
\hline \multirow[t]{2}{*}{ Sample } & \multicolumn{3}{|l|}{ Composition } & \multicolumn{3}{|l|}{ Texture } \\
\hline & Primary minerals & Lithic fragments & Interstitial materials & Microstructure & $\begin{array}{l}\text { Grain size range } \\
(\text { Min-max, } \mu \mathrm{m})\end{array}$ & Shape \\
\hline YG & $\begin{array}{l}\text { Quartz, K-feldspar, } \\
\text { mica }\end{array}$ & $\begin{array}{l}\text { Siliceous rock, rhyolite, } \\
\text { metamorphic argil- } \\
\text { laceous rock }\end{array}$ & $\begin{array}{l}\text { Clay matrix, } \\
\text { calcareous cement }\end{array}$ & $\begin{array}{l}\text { Grain supported, } \\
\text { Pore-filling cementa- } \\
\text { tion }\end{array}$ & $90-2000$ & $\begin{array}{l}\text { From sub-rounded to } \\
\text { sub-angular }\end{array}$ \\
\hline $\mathrm{DZ}$ & $\begin{array}{l}\text { Quartz, K-feldspar, } \\
\text { plagioclase, mica }\end{array}$ & $\begin{array}{l}\text { Siliceous rock, siltite, } \\
\text { micrite, argillaceous } \\
\text { rock, rhyolite }\end{array}$ & & & $20-350$ & Sub-angular \\
\hline LS & $\begin{array}{l}\text { Quartz, K-feldspar, } \\
\text { plagioclase, mica }\end{array}$ & $\begin{array}{l}\text { Siliceous rock, argil- } \\
\text { laceous rock, siltite, } \\
\text { micrite, sericite slate }\end{array}$ & & & $16-710$ & $\begin{array}{l}\text { From sub-rounded to } \\
\text { sub-angular }\end{array}$ \\
\hline
\end{tabular}

intrusion curve. Median pore diameter is defined as the pore diameter at which $50 \%$ of the pore volume in the sample has been intruded by mercury. Average pore diameter is calculated from the total intrusion volume and total pore area measured in MIP. As can be seen, the DZ sample had the narrowest dominant pore diameter range in $0.03-0.6 \mu \mathrm{m}$ with the smallest average pore diameter and median pore diameter among the tested sandstones. Although the average pore diameters of YG and LS samples were quite similar, larger dominant pore diameter range and median pore diameter of the latter indicated its wider pore size distribution.

\section{Capillary absorption coefficient}

For the quantitative analysis of capillary water absorption, the cumulative inflow per unit area $\left(\mathrm{kg} / \mathrm{m}^{2}\right)$ against the square root of time $\left(\mathrm{h}^{0.5}\right)$ is plotted. Ideally, the curve consists of a fast increase stage followed by a slow increase stage, both of which can be approximated by straight lines. The slope of the first stage is then defined as capillary absorption coefficient $A_{\text {cap }}\left(\mathrm{kg} / \mathrm{m}^{2} \cdot \mathrm{h}^{0.5}\right)$ and it is a critical indicator for the water transport properties in materials:

$$
A_{c a p}=\frac{m_{i}-m_{d}}{A \cdot \sqrt{t_{i}}}
$$

where $m_{i}$ is the wet mass of the sample measured successively during the test $(\mathrm{kg}), m_{d}$ is the initial mass of the dry sample $(\mathrm{kg}), A$ is the area of the immersed bottom surface $\left(\mathrm{m}^{2}\right)$, and $t_{i}$ is the duration from the beginning of the test $(\mathrm{h})$.

The results presented in Fig. 7 suggest that, at the beginning of the test, the amount of water absorbed by the sample increased fast for all the tested sandstones. Afterwards, the speed of increase gradually slowed down over time. During the whole absorption process, the LS sample constantly had a higher value of cumulative inflow per unit area compared to the others. When the test was stopped at $17,303 \mathrm{~min}$ (equivalent to 16.98 $\mathrm{h}^{0.5}$ ), this value reached $6.73,8.46$ and $11.47 \mathrm{~kg} / \mathrm{m}^{2}$ for DZ, YG and LS sandstone, respectively. It can be also noticed from Fig. 7 that the initial part of all curves deviated from a perfect linear relationship, which means that the inflection point between the first (fast increase) and second (slow increase) stages of absorption was ambiguous. Such nonlinearity has been regarded as a measure of stone heterogeneity by David et al. [27]. Under this condition, calculating $A_{\text {cap }}$ based on Eq. (1) becomes very difficult due to its strong sensitivity to data selection. After reviewing various data processing methods in the literature, Feng and Janssen [47] suggested that Hall's model [48] and a new model proposed by them were suitable to obtain $A_{\text {cap }}$ especially for materials with irregular capillary absorption patterns.

Hall's model, which factors in the influence of gravity on capillary absorption, can be justified by both the unsaturated flow theory and the "sharp front" theory. It is written as the following equation:

$$
\frac{m_{i}-m_{d}}{A}=A_{\text {cap }} \cdot \sqrt{t_{i}}-m \cdot t_{i}+n
$$

where $m$ and $n$ are fitting parameters.

Feng and Janssen's model [47] also has a solid physical background and it is simplified from the Lambert W-function:

$$
\frac{m_{i}-m_{d}}{A}=A_{\text {cap }} \cdot b \cdot\left(0.5103-1.3849 \cdot e^{-\frac{t_{i}}{b^{2}}-1}\right)^{0.3403}+c
$$

where $b$ and $c$ are fitting parameters.

As shown in Fig. 7, the results of the capillary water absorption test were fitted by each model, respectively. A certain gap existed between the curve fitted by Eq. (2) (Hall's model) and the measured data, particularly for LS sandstone, where its cumulative inflow per unit area was occasionally overestimated or underestimated. In contrast, Eq. (3) (Feng and Janssen's model) had a better 

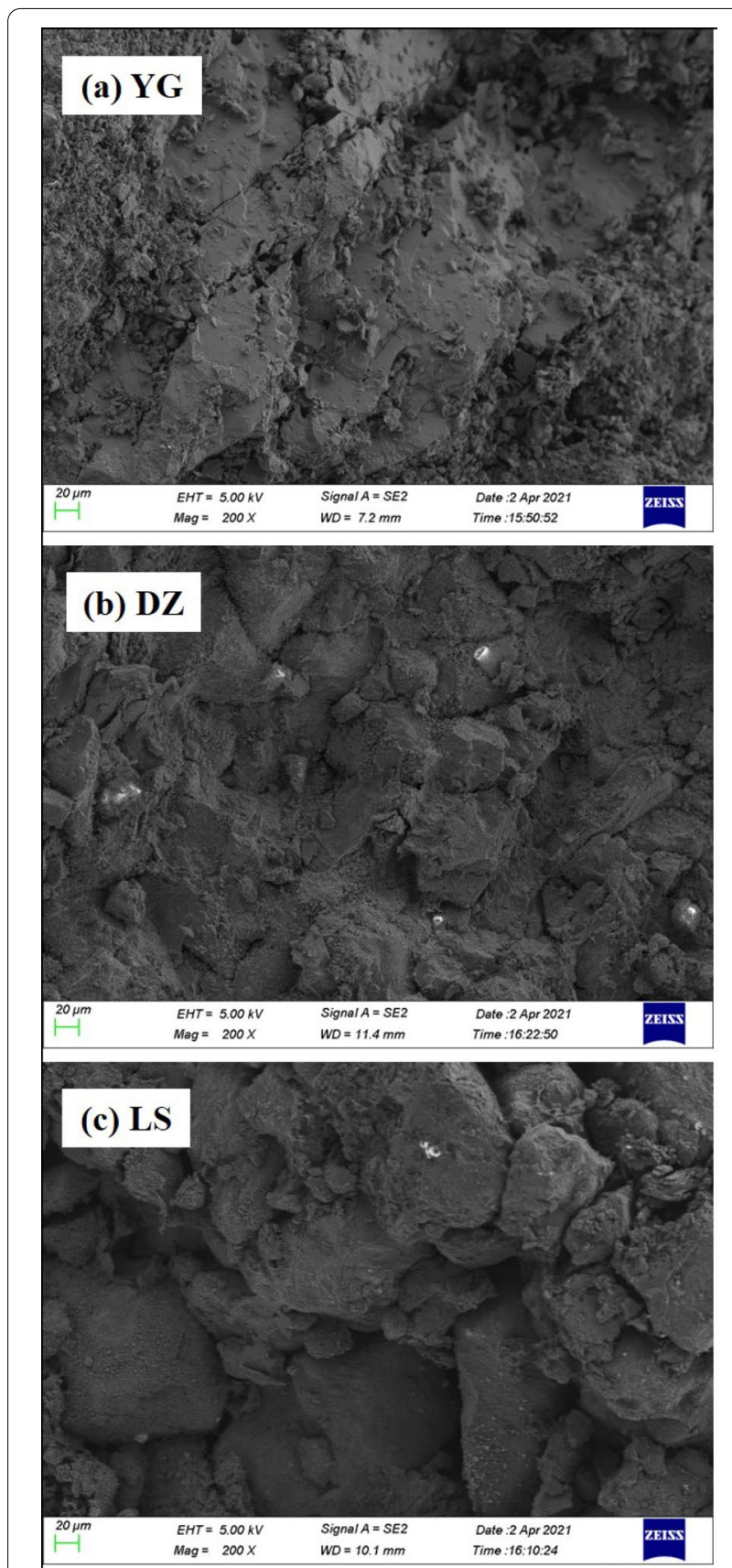

Fig. 5 The SEM microphotographs of the tested sandstones

performance in describing the entire process of capillary absorption for all sandstones with correlation coefficients larger than 0.99 .

For each sandstone, discrepancies existed between capillary absorption coefficients fitted by different models (Table 5). In comparison with Hall's model, Feng and Janssen's model tended to obtain a larger $A_{\text {cap }}$ value, as has been previously reported [47]. The $A_{\text {cap }}$ value was
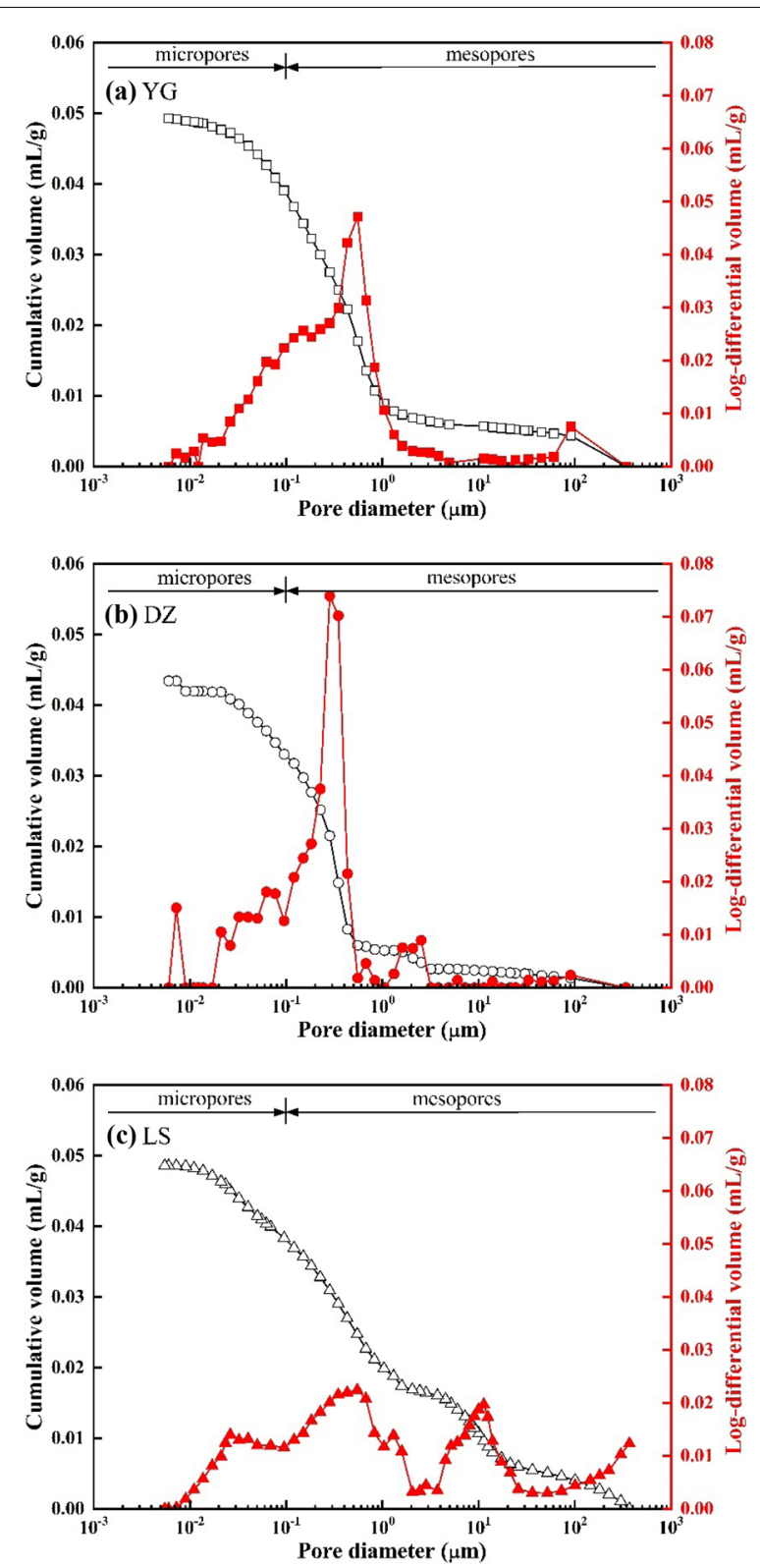

Fig. 6 The cumulative intrusion curves and pore size distribution curves of the tested sandstones

the largest for the LS sample and the smallest for the DZ sample, indicating that the LS sample can absorb water faster than the other two samples. In the literature, the measured $A_{\text {cap }}$ values of sandstones vary from 0.34 to $36.43 \mathrm{~kg} / \mathrm{m}^{2} \cdot \mathrm{h}^{0.5}$, depending on their petrophysical properties [11, 14, 49-51]. Graue et al. [11] divided stones into three groups with low $\left(<0.5 \mathrm{~kg} / \mathrm{m}^{2} \cdot \mathrm{h}^{0.5}\right)$, medium $\left(0.5 \sim 3.0 \mathrm{~kg} / \mathrm{m}^{2} \cdot \mathrm{h}^{0.5}\right)$ and high $\left(>3.0 \mathrm{~kg} / \mathrm{m}^{2} \cdot \mathrm{h}^{0.5}\right)$ capacity of capillary water absorption, respectively. According 
Table 4 Measured parameters on the pore structure of the tested sandstones

\begin{tabular}{|c|c|c|c|c|c|c|c|}
\hline \multirow[t]{3}{*}{ Sample } & \multicolumn{4}{|c|}{ Pore size distribution (\%) } & \multicolumn{3}{|c|}{ Characteristic pore diameter $(\mu \mathrm{m})$} \\
\hline & \multirow{2}{*}{$\begin{array}{l}\text { Micropores } \\
<0.1 \mu \mathrm{m}\end{array}$} & \multicolumn{6}{|c|}{ Mesopores } \\
\hline & & $0.1-1 \mu \mathrm{m}$ & $1-10 \mu \mathrm{m}$ & $>10 \mu \mathrm{m}$ & Dominant range & Average & $\begin{array}{l}\text { Median } \\
\text { (by } \\
\text { volume) }\end{array}$ \\
\hline YG & 25.32 & 56.59 & 6.56 & 11.53 & $0.02 \sim 1$ & 0.119 & 0.362 \\
\hline DZ & 26.86 & 60.98 & 6.66 & 5.50 & $0.03 \sim 0.6$ & 0.088 & 0.282 \\
\hline LS & 21.05 & 38.00 & 18.91 & 22.04 & $0.02 \sim 30$ & 0.115 & 0.573 \\
\hline
\end{tabular}

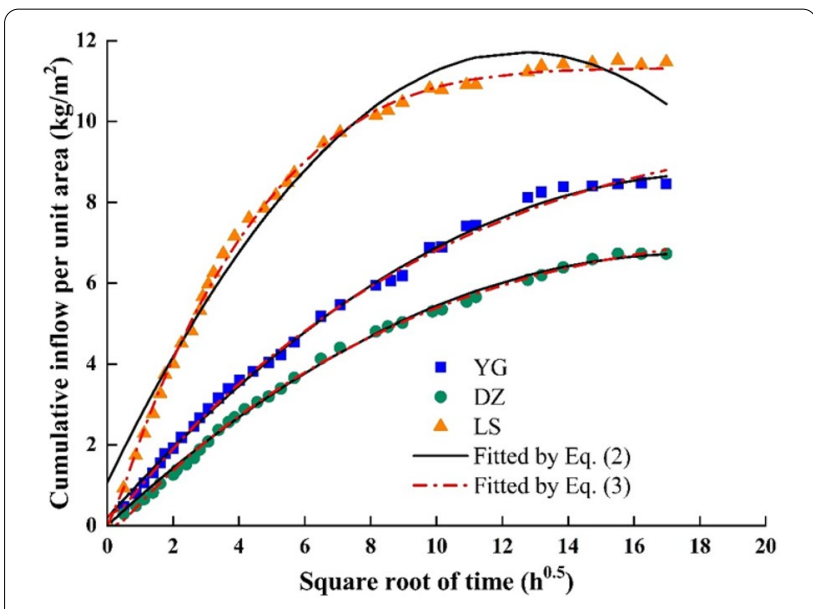

Fig. 7 Evolution of cumulative inflow per unit area of the tested sandstones

to this classification, sandstones tested in this study all showed a medium water absorption capacity.

During the measurement, the gradient of water transport changed at different stages, which resulted in a continuously decreasing water flux. At the end of the test, all samples achieved equilibrium conditions for capillary water absorption. Correspondingly, their capillary moisture contents were calculated in terms of weight in percentage expression, where the total mass of absorbed water was divided by the dry mass of the sample. LS sandstone had a capillary moisture content of $5.03 \%$ and it was more water absorbent than YG (3.47\%) and DZ
(2.92\%) sandstones. It can also be noticed that the value of capillary moisture content for each sandstone was slightly lower than that of forced water absorption, as listed in Table 1, indicating that its final degree of saturation was less than $100 \%$. This is attributed to the fact that the fluid motion in mesopores without dead-end is mainly governed by capillary force [46]. In an evacuation vessel under vacuum condition, however, water can even penetrate in macropores and micropores where the fluid motion is driven by gravity forces and adsorption forces, respectively. Another possible reason why the sample was not fully saturated during capillary imbibition is the entrapment of air bubbles, which easily occurs in porous structures with complex geometries [52]. As for the tested sandstones, their final degrees of saturation after capillary imbibition ranged from $87.8 \%$ to $90.4 \%$, implying a relatively good connectivity between mesopores.

\section{Height of capillary rise}

Figure 8 presents the general views of the tested sandstones exposed to capillary water absorption. It appears that, at the very beginning, no big differences existed in the heights of capillary rise among the three samples. As the test continued, however, the rise of capillary water from the bottom to the upper part became distinctly and visibly slower in DZ sandstone. Another finding is that the interface between the wet and dry zones was relatively planar for both YG and DZ samples. In comparison, the shape of the interface in the LS sample was quite irregular, implying nonuniform water absorption.

Table 5 Fitting parameters of different models

\begin{tabular}{|c|c|c|c|c|c|c|c|c|}
\hline \multirow[t]{2}{*}{ Sample } & \multicolumn{4}{|c|}{ Hall's model } & \multicolumn{4}{|c|}{ Feng and Janssen's model } \\
\hline & $A_{\text {cap }}$ & $m$ & $n$ & $R^{2}$ & $A_{\text {cap }}$ & $b$ & c & $R^{2}$ \\
\hline YG & 0.914 & 0.025 & 0.196 & 0.996 & 0.948 & 14.239 & -0.985 & 0.996 \\
\hline DZ & 0.756 & 0.021 & 0.000 & 0.997 & 0.824 & 12.796 & -1.047 & 0.998 \\
\hline LS & 1.689 & 0.067 & 1.070 & 0.978 & 2.413 & 6.653 & -1.453 & 0.998 \\
\hline
\end{tabular}




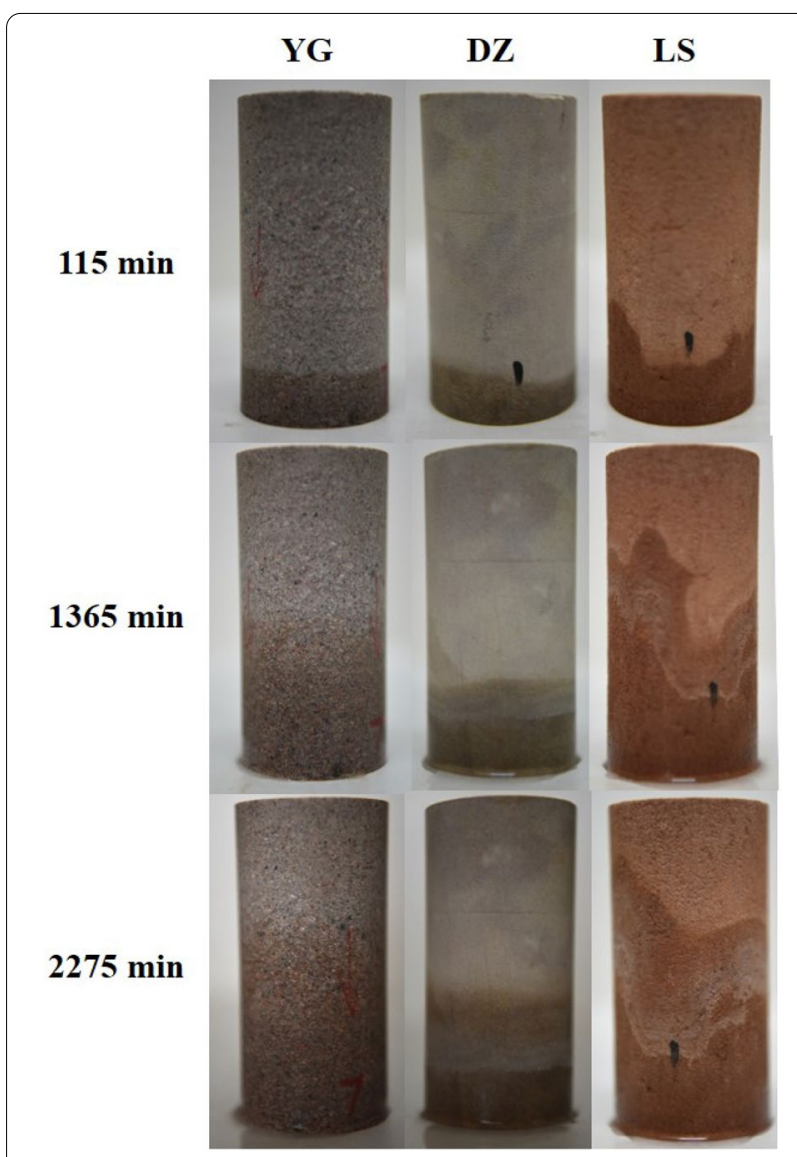

Fig. 8 General views of the tested sandstones during capillary water absorption test

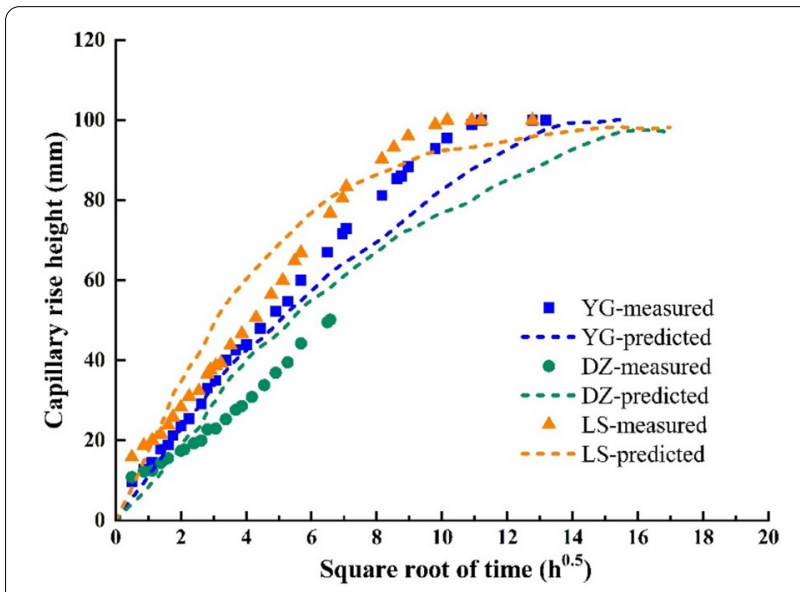

Fig. 9 Variation in the height of capillary rise of the tested sandstones

The variation in the height of capillary rise, measured using a ruler, is illustrated against the square root of time in Fig. 9. The rising speed of the water front was rapid at the initial stage of the test and then gradually decreased over time. As expected, the water rose to a higher level in the YG and LS samples compared to the DZ sample in the same amount of time. When compared with the curves in Fig. 7, it can also be noticed that visual saturation occurred before mass saturation for these two sandstones. More specifically, the sample mass continued to increase through water absorption, after the visual capillary front on the surface of the sample already reached the top. In fact, this process is correlated with moisture redistribution in the microstructure. Through diffusion of some entrapped air bubbles, water could then more deeply penetrate into pores and even clay minerals. The lack of measured data for DZ sandstone at the later period of the test is related to the minimal contrast in color between the wet and dry zones. Hence, it was very difficult to visually determine the exact height of capillary rise at the surface of sample. It has been previously reported that, especially for stones with very small porosity and/or dark color, the water front potentially becomes nearly invisible [29].

Capillary rise height $(h)$ can also be predicted directly from the mass data using [27]:

$$
h=\frac{m_{i}-m_{d}}{\rho_{w} S \phi A}
$$

where $\rho_{w}$ is the water density $\left(\mathrm{kg} / \mathrm{m}^{3}\right), S$ is the water saturation in the invaded region, and $\phi$ is the porosity. For each sample, the final degree of saturation through capillary rise was adopted as $S$ value. As shown in Fig. 9, the predicted curve of YG sandstone correlates well with its measured data particularly during the first half of the test. For both DZ and LS samples, however, the predicted curve occasionally over- or underestimated the measured data. In fact, Eq. 4 makes two assumptions, i.e., the water front is perfectly horizontal and $S$ remains the same everywhere in the water invaded region at any time. This suggests a piston-like imbibition process in the sample. However, as observed in the LS sample, this is generally not true due to the heterogeneity of stone, where the water front can be quite irregular. Variations in the geometry of water-air interface (planar or curvature) at different stages of capillary imbibition are common in sandstones [27, 28]. Interestingly, the water-air interface became less flat or rounder (i.e., with smaller radius of curvature) when the capillary rise in the sample was faster. It has also been reported by Tsunazawa et al. [20] that $S$ was neither homogeneous in the sandstone samples nor constant throughout the absorption test. For these reasons, a discrepancy between the measured capillary rise heights and the curve predicted from the mass data is to be expected. 
Thermography images of the tested sandstones taken during the test are shown in Fig. 10. Considering the almost constant room conditions, the nonuniform surface temperature of the samples can be attributed to differences in spatial distribution of the water content. Due to the one-dimensional capillary rise of water, as expected, lower temperature values (dark blue color) were measured at the bottom part of sample where it had already absorbed water. The degree of saturation of the sample gradually decreased with increasing height so that its surface temperature also increased from the bottom to the top by a few degrees centigrade. During the imbibition process, particularly on DZ and LS samples, a transitional zone of temperature above the wetted portion can be observed, showing light blue color in thermography images. A similar phenomenon has also been reported by Barreira et al. [34]. Using electrical resistance measurement, Hassine et al. [29] verified the relationship between such transition area and the local variation in water saturation close to the water front. It can be attributed to the moisture transfer by vapor diffusion through the pore network, as well as vapor condensation in smaller pores between the wet and dry portions. As time passed, continuous water absorption resulted in a progressive rise of the water front which was indicated by an expanding area of the wetted portion. After the saturation through capillary action, the temperature of the entire sandstone samples decreased and gradually became uniform, implying a progressively homogeneous water distribution.

\section{Microstructural interpretation of capillary water absorption characteristics}

For the spontaneous upward motion of water in porous materials, the net driving force mainly depends on two different forces with opposite effects, i.e., capillary force and gravity force. A dimensionless Bond $\left(B_{O}\right)$ number has been proposed to assess the relative importance of gravity force towards capillary force [53]:

$$
B_{O}=\frac{\Delta \rho g a^{2}}{\sigma}
$$

where $\Delta \rho$ is the density difference between the two fluids $\left(\mathrm{kg} / \mathrm{m}^{3}\right), g$ is the acceleration due to gravity $\left(\mathrm{m} / \mathrm{s}^{2}\right), \sigma$ is the liquid-gas surface tension $(\mathrm{N} / \mathrm{m})$ and $a$ is a characteristic length $(\mathrm{m})$ (e.g., mean pore radius, fracture aperture). For the tested sandstones, very small values of $B_{O}$ with the order of $10^{-10}$ were obtained when considering the average pore size derived from the MIP test (Table 4). Hence, their water imbibition process can be considered to be dominated by the capillary force whereas the influence of gravity force is negligible.

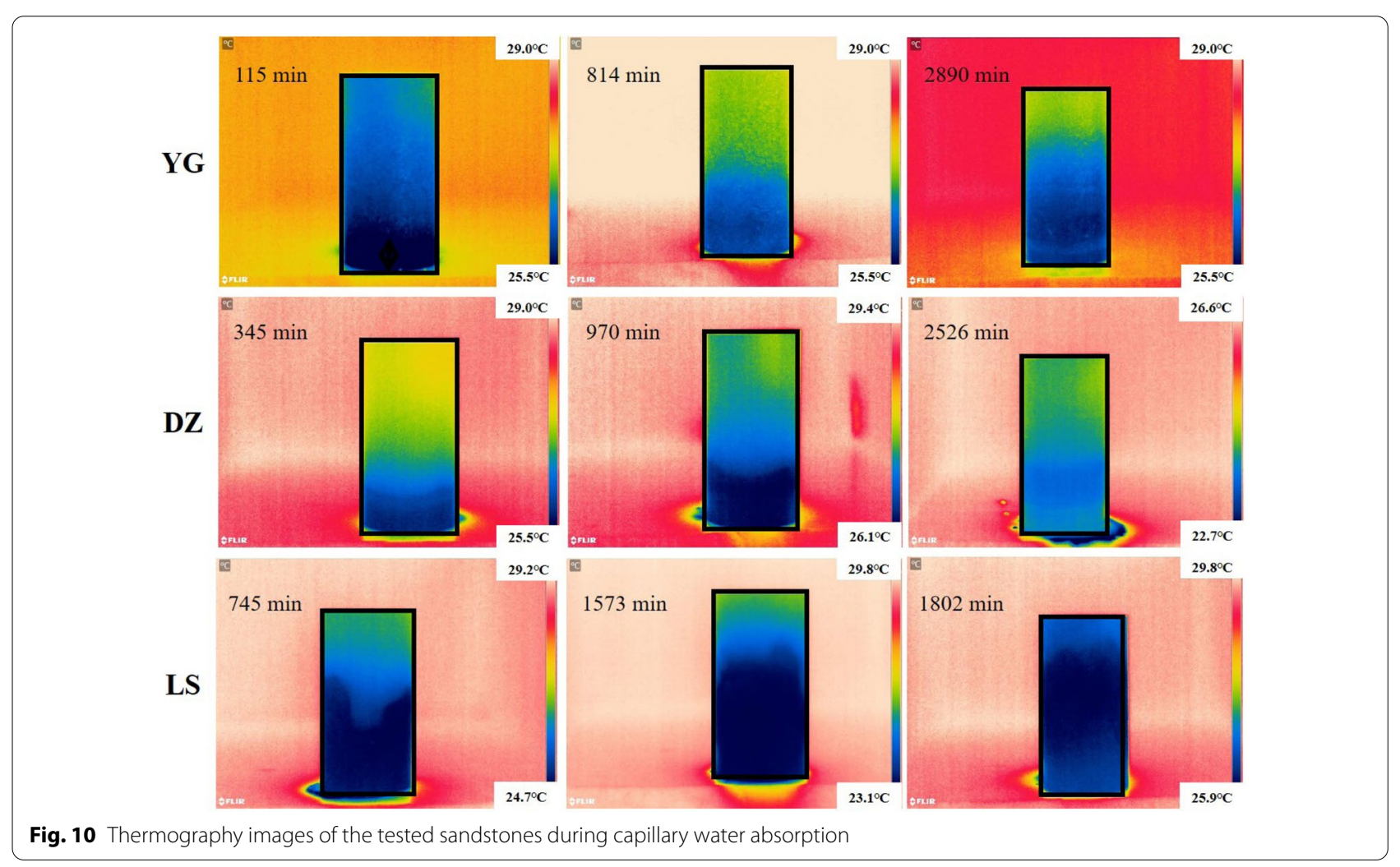


For incompressible Newtonian liquid under a quasisteady state and fully developed laminar flow with noslip boundary conditions in a straight capillary tube of circular cross-sectional shape, the volumetric flow rate $q$ $\left(\mathrm{m}^{3} / \mathrm{s}\right)$ can be described by the classical Hagen-Poiseuille equation:

$$
q=\frac{\pi r^{4}}{8 \mu} \cdot \frac{\Delta P}{l}
$$

where $\Delta P$ is the pressure differential between the inlet and outlet of the tube (Pa), $\mu$ is the fluid viscosity $(\mathrm{Pa} \cdot \mathrm{s})$, $l$ and $r$ is the length and radius of the capillary tube (m), respectively.

According to the Young-Laplace equation, $\Delta P$ induced by the meniscus, known as the capillary pressure, is correlated to the size of the tube as follows:

$$
\Delta P=\frac{2 \sigma \cos \theta}{r}
$$

where $\theta$ is the water-solid contact angle.

Hence, the water front moves at a rate of $v(\mathrm{~m} / \mathrm{s})$ :

$$
\nu=\frac{q}{\pi r^{2}}=\frac{r \sigma \cos \theta}{4 \mu l}
$$

By combining Eqs. (6)-(8), Lucas-Washburn (L-W) equation is obtained:

$$
l=\sqrt{\frac{r \sigma \cos \theta}{2 \mu} t}
$$

The L-W equation is fundamental for quantitative analysis of capillary rise in porous materials. The radius of the capillary tube $(r)$ in equations was previously assumed to be in accordance with the pore radius at the peak of the PSD curve [20,54]. However, this fails to properly reproduce the experimentally obtained height-versus-time data properly for various stones. Instead, for better simulation, a value of $r$ several orders of magnitude smaller than the dominant pore radius obtained via MIP should be considered. In fact, a natural geologic medium such as sandstone consists of pores with varied shape and size, whereas the L-W equation assumes a simplified medium. The true process of capillary imbibition is significantly affected by numerous complex microstructural features such as tortuosity of pores, non-circularity of the cross section of pores, non-uniformity of pore radius, variation of contact angle, inertial effect and pore wall roughness [55-59]. Yokoyama et al. [52] proposed a model that considers both pore branching and pore radius variation, verifying that at branch points, narrower pores serve as preferential flow path for the rising water due to their greater capillary pressure. If water in the narrower pore reaches the next junction earlier, air bubbles are likely to be trapped in the wider pore. Moreover, in pores with varying cross sections, the driving force of water becomes relatively weaker at wider parts. As a consequence, the rate of capillary rise in such pores is much slower than that in a consistently narrow but uniform pores.

Basically, porous structures are constituted by two distinct elements, i.e., pore chambers and pore throats, where the chambers are placed between the throats. Pore chambers have higher volume so that they account for most of the stones porosity and control the storage of fluids. The transportation of fluids, however, is mainly governed by the dimension and connectivity of pore throats. Razavifar et al. [60] pointed out that MIP data can provide a rough estimate of the throat size distribution in porous skeletons. In the present study, DZ sandstone exhibited much lower kinetics for evolution of both absorbed water mass and height of capillary rise during imbibition, which can be explained by its smaller average and median pore diameters. Undoubtedly, capillary water tends to rise faster in larger pores because the overall path for water motion widens. As for YG and LS sandstones, despite their similar average pore diameters, the water absorption process in the YG sample was obviously retarded. This is attributed to the lower percentage of mesopores in YG sandstone that play an essential role in capillary imbibition.

Dincer and Bostanci [4] categorized the PSD curves of stones into three types as uniform, semi-uniform and non-uniform. For a uniform PSD curve, the dominant pore diameter range lies in a relatively narrow zone. In their study, ignimbrites with uniform pore sizes around 5-10 $\mu \mathrm{m}$ had larger capillary absorption coefficients than those with semi-uniform and non-uniform PSD curves, indicating higher potential for water uptake. When the dominant pore diameter became smaller than $1 \mu \mathrm{m}$, however, the capillary absorption coefficient of the sample with uniform PSD was greatly reduced. This is due to the fact that the flow resistance in these small pores is relatively high. In addition, instead of capillary imbibition, condensation related to adsorption forces might occur in smaller pores slowing down the transportation of liquid water. It is also noteworthy that stones with non-uniform PSD are likely to behave in a heterogeneous way [27]. Hence, compared to other sandstones, the LS sample exhibited a more irregular shaped water front with less homogeneous distribution of water saturation.

From the perspective of minerology, pores in sandstone have been classified into four types: residual interparticle pores (normally in the micron scale), grain dissolution pores (ranging from hundreds of nanometers to the particle size of individual feldspar grains), clay dominated pores (at the nanoscale) and micro fractures [61]. 
Typically, the interparticle pores are fewer and scattered whereas the clay-dominated pores are much smaller and continuously distributed. The effects of clay minerals on the porous structure of stones vary depending on the type, content and occurrence of clay minerals. It has been found that kaolinite, typically observed as vermicular aggregate, exerts a negative impact on the porosity. Similarly, illite and mixed layer of illite/smectite act as an obstruction to the interparticle pore spaces because of their fibrous or webby morphology [61].

By investigating the fluid flow capacity of sandstone in detail, Qiao et al. [62] reported that the mineralogy influenced flow and spatial distribution of fluids via two decisive intrinsic factors, namely, pore geometry (pore radius) and wettability (surface tension, contact angle). With increasing clay content, the contribution of macropores to the porosity was reduced whereas the contribution of micropores was increased due to the formation of large quantities of intercrystalline pores. Besides, clay minerals had stronger hydrophilic properties compared to framework grains such as quartz and feldspar. It is worth mentioning that the negative impact of illite and mixed layer of illite/smectite on the fluid flow capacity of sandstone is higher than that of chlorite and kaolinite. Interestingly, as reported by Xiao et al. [63], an increase in clay content caused no significant reduction in the total porosity of the stone, indicating that clay dominated pores can partly compensate for the loss of interparticle pores. Meanwhile, for both macropores and micropores, the complexity of their morphologies and arrangements (such as roughness, shapes and distribution) was enhanced by a higher clay content which increased the heterogeneity of the material.

Another fact that should be recognized is that clay minerals, when interacting with water, tend to expand and thereby possibly occlude the pore space and obstruct the pore throats connecting them. Consequently, during capillary imbibition, the effective size and connectivity of the flow paths in the samples might be reduced whereas the tortuosity and heterogeneity are further increased. As discussed before, the texture of all the tested sandstones was grain-supported, with clay matrix and calcareous cement filling the pore spaces partly/completely or coating the framework grains (Table 3). Although the clay content in the YG sample was the highest among three sandstones, it was dominated by non-expanding kaolinite. LS sandstone had a relatively higher content of illite and mixed layer of illite/smectite, which potentially exerted more significant influences on the fluid flow capacity. Larger numbers of mesopores in the LS sample (especially those $>1 \mu \mathrm{m}$ ) might compensate for the unfavorable effects of clay minerals on the capillary water absorption to some extent. However, a more obvious heterogeneity was noticed in this sandstone compared to YG and DZ sandstones.

\section{Implications for grotto heritage sites}

The capillary absorption coefficient and the rate of capillary rise are important indicators for the susceptibility of building stones to deterioration. Larger values of these parameters indicate higher fluid flow capacity, suggesting a greater potential of the material for massive and fast water uptake from the surroundings. In reality, capillary water absorption happens in various scenarios, for instance, when the stone is exposed either to water rising from the ground or wind-driven rainfall. The water transport distance primarily depends on its petrographic and petrophysical properties.

As a detrimental factor, water plays an essential role in directly exerting adverse impacts on stones by impairing their mechanical behavior through softening and swelling $[64,65]$. When considering the horizontal input of water, shear stress might be induced at the discontinuity between the wet outer layer and the dry inner core. After repeated wetting-drying cycles, progressive loss of stone surfaces tends to occur in form of spalling decay. Water can also act as a transport vehicle of chemical substances such as soluble salts and atmospheric polluting agents. Many pathologies, e.g., powdering, alveolarization, detachment, discoloration, deposits, efflorescence and subflorescence, can be attributed to the presence of salts. These phenomena become visible only when enough salts have accumulated within the stone. The porous structure not only governs the transport of fluids in terms of quantity and distribution, but also affects the pressure generated on the pore walls during salt crystallization [66, 67]. Although different stone types might have similar capillary water absorption characteristics, they actually correspond to quite distinct pore structure systems and flow paths. Changes in microstructure and the resulting capillary water absorption capacity could potentially induce significant discrepancies in the long-term durability of the stone.

Even for a specific stone, its capillary water absorption characteristics do not remain the same over time. For grotto heritage sites exposed to the natural environment, the intrinsic parameters of the material such as grain size, sorting, mineral composition, porosity, pore size distribution and homogeneity are continuously modified and complicated by environmental factors (e.g., rainfall, temperature, relative humidity, wind, solar radiation and microorganism). Such weathering effects might strengthen, retain or damage the material's macroscopic behavior including capillary water absorption. Understanding the underlying science to stone weathering processes in more detail lies an essential basis for fully 
comprehending the deterioration mechanisms at grotto heritage sites.

\section{Conclusions}

This study investigated the capillary water absorption of sandstones from valuable World Heritage Sites in China, i.e., Yungang Grottoes, Dazu Rock Carvings and Leshan Grand Buddha. Tests were conducted on small columns to monitor the variation in the mass of the samples and the height of capillary rise during water imbibition. The following conclusions can be drawn.

Increase in the amount of water absorbed by the samples was fast at the beginning, which then gradually slowed down over time. During the whole absorption process, LS sandstone constantly had a higher value of cumulative inflow per unit area compared to the others. As an indicator for the water transport properties in materials, the measured capillary absorption coefficient showed that all the tested sandstones had a medium water absorption capacity.

The water rose to a higher level in the YG and LS samples compared to the DZ sample in the same amount of time. The shape of water front was relatively planar for both YG and DZ samples, which became quite irregular in the LS sample. Minimal contrast in color between the wet and dry zones of DZ sandstone induced difficulties in determining the exact height of capillary rise at the surface of the sample. Infrared thermography proved to be a practical method for monitoring the water uptake process without causing any interference in the test procedure or damage to the sample. It was able to detect subtle signs that were not visible to the naked eye.

The kinetics of water transport by capillary action was the fastest for LS sandstone and the slowest for DZ sandstone. The differences in macroscopic properties can be attributed to their different pore structure features, such as average pore size and pore size distribution. With increasing average pore diameter, the overall flow paths were widened to facilitate water rising in the sample, whereas a wider pore size distribution with multiple peak pore diameters tended to increase its heterogeneity. In addition, factors such as the type and content of clay minerals also exerted influences on the porous structure of sandstones in various degrees.

Despite these preliminary results in the laboratory, there are still many open questions regarding the actual behaviors of sandstones under complex environmental conditions in the field. As the sandstone keeps changing over time, qualitative and quantitative analysis of the correlation between the capillary water absorption characteristics and its petrophysical features at various weathering stages would also be an interesting subject for the future. Advantages of infrared thermography (portable device, simple operation, instant measurement etc.) exhibit a tremendous potential in detecting temporal and spatial changes in the moisture distribution. Comprehensive research, conducted both indoors and outdoors, is challenging but necessary to clarify the deterioration and the relevant physical and chemical processes.

\section{Acknowledgements}

The authors sincerely appreciate Yungang Academy, Academy of Dazu Rock Carvings and Grottoes Research Center of Management Committee of Leshan Grand Buddha Scenic Spot for providing help in performing sandstone sampling. Dr Gesa Schwantes is gratefully acknowledged for her assistance in revising and improving the manuscript. We also wish to express our gratitude to all anonymous reviewers and the handling editor who gave constructive comments.

\section{Authors' contributions}

YZ set up the whole experimental program, analyzed the data, drafted and revised the manuscript. YZ conducted the tests and analyzed the data. JH reviewed the manuscript and provided support and guidance for this work. All authors read and approved the final manuscript.

\section{Funding}

This work was supported by the National Natural Science Foundation of China (42007265), the National Key Research and Development Program of China (2019YFC1520500), and the China Postdoctoral Science Foundation (2020M671075).

\section{Availability of data and materials}

The datasets used and/or analyzed during the current work are given either in the text or in the cited references.

\section{Declarations}

\section{Competing interests}

The authors declare that they have no competing interests.

\section{Author details}

${ }^{1}$ Shanghai Institute of Applied Mathematics and Mechanics, School of Mechanics and Engineering Science, Shanghai University, Shanghai 200444, China. ${ }^{2}$ Institute for the Conservation of Cultural Heritage, Shanghai University, Shanghai 200444, China.

Received: 25 October 2021 Accepted: 27 January 2022

Published online: 15 February 2022

\section{References}

1. Siedel H, Pfefferkorn S, von Plehwe-Leisen E, Leisen H. Sandstone weathering in tropical climate: results of low-destructive investigations at the temple of Angkor Wat, Cambodia. Eng Geol. 2010;115(3-4):182-92.

2. Feuer M, Ince I. Effects of the freeze-thaw (F-T) cycle on the andesitic rocks (Sille-Konya/Turkey) used in construction building. J Afr Earth Sci. 2015;109:96-106

3. Ozvan A, Dinçer I, Akin M, Oyan V, Tapan M. Experimental studies on ignimbrite and the effect of lichens and capillarity on the deterioration of Seljuk Gravestones. Eng Geol. 2015;185:81-95.

4. Dincer I, Bostanci M. Capillary water absorption characteristics of some Cappadocian ignimbrites and the role of capillarity on their deterioration. Environ Earth Sci. 2019;78(1):7

5. Waragai T, Hiki Y. Influence of microclimate on the directional dependence of sandstone pillar weathering in Angkor Wat temple, Cambodia. Prog Earth Planet Sci. 2019;6:10.

6. Germinario L, Oguchi CT, Tamura Y, Ahn S, Ogawa M. Taya Caves, a Buddhist marvel hidden in underground Japan: stone properties, deterioration, and environmental setting. Herit Sci. 2020;8(1):87. 
7. Benavente D, de Jongh M, Canaveras JC. Weathering processes and mechanisms caused by capillary waters and pigeon droppings on porous limestones. Minerals. 2021;11(1):18.

8. Celik MY, Sert M. An assessment of capillary water absorption changes related to the different salt solutions and their concentrations ratios in the Doger tuff (Afyonkarahisar-Turkey) used as building stone of cultural heritages. J Build Eng. 2021;35:102102.

9. Yan SJ, Xie N, Liu JH, Li L, Peng LZ, Jiang SW. Salt weathering of sandstone under dehydration and moisture absorption cycles: an experimental study on the sandstone from Dazu rock carvings. Earth Surf Process Landf. 2022. https://doi.org/10.1002/esp.5298.

10. Vazquez P, Alonso FJ, Esbert RM, Ordaz J. Ornamental granites: relationships between $\mathrm{p}$-waves velocity, water capillary absorption and the crack network. Constr Build Mater. 2010;24(12):2536-41.

11. Graue B, Siegesmund S, Middendorf B. Quality assessment of replacement stones for the Cologne Cathedral: mineralogical and petrophysical requirements. Environ Earth Sci. 2011;63(7-8):1799-822.

12. Tomasic I, Lukic D, Pecek N, Krsinic A. Dynamics of capillary water absorption in natural stone. Bull Eng Geol Environ. 2011;70(4):673-80.

13. Cobanoglu I. Prediction and identification of capillary water absorption capacity of travertine dimension stone. Arab J Geosci. 2015;8(11):10135-49.

14. Molina E, Benavente D, Sebastian E, Cultrone G. The influence of rock fabric in the durability of two sandstones used in the Andalusian Architectural Heritage (Montoro and Ronda, Spain). Eng Geol. 2015;2015(197):67-81.

15. Celik MY. Water absorption and P-wave velocity changes during freezethaw weathering process of crosscut travertine rocks. Environ Earth Sci. 2017;76(12):409.

16. Ince I. Relationship between capillary water absorption value, capillary water absorption speed, and capillary rise height in pyroclastic rocks. Mining Metall Explor. 2021;38(2):841-53.

17. Ioannou I, Charalambous C, Hall C. The temperature variation of the water sorptivity of construction materials. Mater Struct. 2017;50(5):208.

18. Celik MY, Kacmaz AU. The investigation of static and dynamic capillary by water absorption in porous building stones under normal and salty water conditions. Environ Earth Sci. 2016;75(4):307.

19. Karoglou M, Moropoulou A, Giakoumaki A, Krokida MK. Capillary rise kinetics of some building materials. J Colloid Interface Sci. 2005;284(1):260-4.

20. Tsunazawa Y, Yokoyama T, Nishiyama N. An experimental study on the rate and mechanism of capillary rise in sandstone. Prog Earth Planet Sci. 2016;3:8.

21. Bortolotti V, Camaiti M, Casieri C, De Luca F, Fantazzini P, Terenzi C. Water absorption kinetics in different wettability conditions studied at pore and sample scales in porous media by NMR with portable single-sided and laboratory imaging devices. J Magn Reson. 2006;181(2):287-95.

22. Lai FP, Li ZP, Wei Q, Zhang TT, Zhao QH. Experimental investigation of spontaneous imbibition in a tight reservoir with nuclear magnetic resonance testing. Energy Fuels. 2016;30(11):8932-40.

23. Fu TF, Xu T, Heap MJ, Meredith PG, Yang TH, Mitchell TM, Nara Y. Analysis of capillary water imbibition in sandstone via a combination of nuclear magnetic resonance imaging and numerical DEM modeling. Eng Geol. 2021;285:106070.

24. Dewanckele J, De Kock T, Fronteau G, Derluyn H, Vontobel P, Dierick M, Van Hoorebeke L, Jacobs $\mathrm{P}$, Cnudde V. Neutron radiography and X-ray computed tomography for quantifying weathering and water uptake processes inside porous limestone used as building material. Mater Charact. 2014;88:86-99.

25. Zhao YX, Xue SB, Han SB, Chen ZW, Liu SM, Elsworth D, He LF, Cai J, Liu $Y T$, Chen DF. Effects of microstructure on water imbibition in sandstones using X-ray computed tomography and neutron radiography. J Geophys Res-Solid Earth. 2017;122(7):4963-81.

26. Raneri S, Barone G, Mazzoleni P, Rabot E. Visualization and quantification of weathering effects on capillary water uptake of natural building stones by using neutron imaging. Appl Phys A Mater Sci Process. 2016;122(11):969.

27. David C, Menendez B, Mengus JM. X-ray imaging of water motion during capillary imbibition: geometry and kinetics of water front in intact and damaged porous rocks. J Geophys Res-Solid Earth. 2011;116:B03204.
28. David C, Bertauld D, Dautriat J, Sarout J, Menendez B, Nabawy B. Detection of moving capillary front in porous rocks using $X$-ray and ultrasonic methods. Front Phys. 2015;3:53.

29. Hassine MA, Beck K, Brunetaud X, Al-Mukhtar M. Use of electrical resistance measurement to assess the water saturation profile in porous limestones during capillary imbibition. Constr Build Mater. 2018;165:206-17.

30. Grinzato E, Cadelano G, Bison P. Moisture map by IR thermography. J Mod Opt. 2010;57(18):1770-8.

31. Ludwig N, Rosina E, Sansonetti A. Evaluation and monitoring of water diffusion into stone porous materials by means of innovative IR thermography techniques. Measurement. 2018;118:348-53.

32. Zhang F, Zhang XL, Li YJ, Tao ZG, Liu WF, He MC. Quantitative description theory of water migration in rock sites based on infrared radiation temperature. Eng Geol. 2018;241:64-75.

33. Avdelidis NP, Moropoulou A, Theoulakis P. Detection of water deposits and movement in porous materials by infrared imaging. Infrared Phys Technol. 2003;44(3):183-90.

34. Barreira E, Almeida RMSF, Delgado JMPQ. Infrared thermography for assessing moisture related phenomena in building components. Constr Build Mater. 2016:110:251-69.

35. Morillas H, Garcia-Galen J, Maguregui M, Garcia-Florentino C, Marcaida I, Carrero JA, Madariaga JM. In-situ multianalytical methodology to evaluate the conservation state of the entrance arch of La Galea Fortress (Getxo, north of Spain). Microchem J. 2016;128:288-96.

36. Ince I, Bozdag A, Tosunlar MB, Hatir ME, Korkanc M. Determination of deterioration of the main façade of the Ferit Paşa Cistern by non-destructive techniques (Konya, Turkey). Environ Earth Sci. 2018:77(11):420.

37. Ince I, Korkanc M, Hatir ME. Evaluation of weathering effects due to surface and deep moisture in a Roman rock tomb: Lukianos Monument Konya (Turkey). Mediter Archaeol Archaeom. 2020;20(3):121-33.

38. Orr SA, Fusade L, Young M, Stelfox D, Leslie A, Curran J, Viles H. Moisture monitoring of stone masonry: a comparison of microwave and radar on a granite wall and a sandstone tower. J Cult Herit. 2020;41:61-73.

39. Geng H, Zhang SJ, Zhi JH, Zhang RP, Ren JG, Ro CU. Acid solution decreases the compressional wave velocity of sandstone from the Yungang Grottoes, Datong, China. Herit Sci. 2019;7:4.

40. Guo F, Jiang GH. Investigation into rock moisture and salinity regimes: implications of sandstone weathering in Yungang Grottoes, China. Carbonates Evaporites. 2015;30(1):1-11

41. Li ZM, Wang LL, Chen HL, Ma QL. Degradation of emerald green: scientific studies on multi-polychrome Vairocana Statue in Dazu Rock Carvings, Chongqing, China. Herit Sci. 2020;8(1):64.

42. Zhang JK, Huang JP, Liu JH, Jiang SW, Li L, Shao MS. Surface weathering characteristics and degree of Niche of Sakyamuni Entering Nirvana at Dazu Rock Carvings. China Bull Eng Geol Environ. 2019;78(6):3891-9.

43. Xie LN, Zhang BJ, Hu YL. A novel method of preparing a standard weathered sandstone specimen: a case study of red sandstone from the Leshan Giant Buddha (Sichuan, China). Int J Archit Herit. 2021. https://doi.org/10. 1080/15583058.2021.1942591.

44. BS-EN 13755. Natural stone test methods-Determination of water absorption at atmospheric pressure. BSI, London. 2008.

45. BS-EN. Natural stone test methods-determination of real density and apparent density, and of total and open porosity. London: BSI; 1936. p. 2006.

46. Benavente D, del Cura MAG, Bernabeu A, Ordonez S. Quantification of salt weathering in porous stones using an experimental continuous partial immersion method. Eng Geol. 2001;59(3-4):313-25.

47. Feng $\mathrm{C}$, Janssen $\mathrm{H}$. Hygric properties of porous building materials (III): Impact factors and data processing methods of the capillary absorption test. Build Environ. 2018:134:21-34.

48. Hall C, Tse TKM. Water movement in porous building materials-VII. The sorptivity of mortars. Build Environ. 1986;21(2):113-8.

49. Benavente D, Cueto N, Martinez-Martinez J, del Cura MAG, Canaveras $J C$. The influence of petrophysical properties on the salt weathering of porous building rocks. Environ Geol. 2007;52:215-24.

50. Vazquez P, Alonso FJ, Carrizo L, Molina E, Cultrone G, Blanco M, Zamore I. Evaluation of the petrophysical properties of sedimentary building stones in order to establish quality criteria. Constr Build Mater. 2013;41:868-78.

51. Stuck HL, Platz T, Muller A, Siegesmund S. Natural stones of the SaaleUnstrut Region (Germany): petrography and weathering phenomena. Environ Earth Sci. 2018:77(8):300. 
52. Yokoyama T, Yorimoto M, Nishiyama N. Flow path selection during capillary rise in rock: Effects of pore branching and pore radius variation. Transp Porous Media. 2020;135(1):79-99.

53. Or D. Scaling of capillary, gravity and viscous forces affecting flow morphology in unsaturated porous media. Adv Water Resour. 2008;31(9):1129-36

54. Dullien FAL, El-Sayed MS, Batra VK. Rate of capillary rise in porous media with nonuniform pores. J Colloid Interface Sci. 1977;60(3):497-506.

55. Benavente D, Lock P, Del Cura MAG, Ordonez S. Predicting the capillary imbibition of porous rocks from microstructure. Transp Porous Media. 2002:49(1):59-76.

56. Liou WW, Peng YQ, Parker PE. Analytical modeling of capillary flow in tubes of nonuniform cross section. J Colloid Interface Sci. 2009;333(1):389-99.

57. Cai JC, Perfect E, Cheng CL, Hu XY. Generalized modeling of spontaneous imbibition based on Hagen-Poiseuille flow in tortuous capillaries with variably shaped apertures. Langmuir. 2014;30(18):5142-51.

58. Heshmati M, Piri M. Experimental investigation of dynamic contact angle and capillary rise in tubes with circular and noncircular cross sections. Langmuir. 2014;30(47):14151-62.

59. Wu Y, Zhao YX, Li P. Effect of the heterogeneity on sorptivity in sandstones with high and low permeability in water imbibition process. Processes. 2019;7(5):260.

60. Razavifar M, Mukhametdinova A, Nikooee E, Burukhin A, Rezaei A, Cheremisin A, Riazi M. Rock porous structure characterization: a critical assessment of various state-of-art techniques. Transp Porous Media. 2021:136(2):431-56.

61. Zhao HW, Ning ZF, Zhao TY, Zhang R, Wang Q. Effects of mineralogy on petrophysical properties and permeability estimation of the Upper Triassic Yanchang tight oil sandstones in Ordos Basin. Northern China Fuel. 2016:186:328-38

62. Qiao JC, Zeng JH, Ma Y, Jiang S, Feng S, Hu HT. Effects of mineralogy on pore structure and fluid flow capacity of deeply buried sand stone reservoirs with a case study in the Junggar Basin. J Pet Sci Eng. 2020;189:106986

63. Xiao DS, Jiang S, Thul D, Lu SF, Zhang LC, Li B. Impacts of clay on pore structure, storage and percolation of tight sandstones from the Songliao Basin, China: implications for genetic classification of tight sandstone reservoirs. Fuel. 2018;211:390-404

64. Berthonneau J, Bromblet P, Cherblanc F, Ferrage E, Vallet JM, Grauby O. The spalling decay of building bioclastic limestones of Provence (South East of France): from clay minerals swelling to hydric dilation. J Cult Herit. 2016;17:53-60.

65. Potzl C, Dohrmann R, Siegesmund S. Clay swelling mechanism in tuff stones: an example of the Hilbersdorf Tuff from Chemnitz Germany. Environ Earth Sci. 2018;77(5):188.

66. Nasri F, Boumezbeur A, Benavente D. Influence of the petrophysical and durability properties of carbonate rocks on the deterioration of historic constructions in Tebessa (northeastern Algeria). Bull Eng Geol Environ. 2019;78(6):3969-81

67. Thomachot-Schneider C, Vazquez P, Gommeaux M, Lelarge N, Conreux A, Drothiere X, Mouhoubi K, Bodnar JL. Thermal response of building stones contaminated with salts. Constr Build Mater. 2019;226:331-44.

\section{Publisher's Note}

Springer Nature remains neutral with regard to jurisdictional claims in published maps and institutional affiliations.

\section{Submit your manuscript to a SpringerOpen ${ }^{\odot}$ journal and benefit from:}

- Convenient online submission

- Rigorous peer review

- Open access: articles freely available online

- High visibility within the field

- Retaining the copyright to your article

Submit your next manuscript at $\boldsymbol{\nabla}$ springeropen.com 